\title{
A Framework for Versatile Shape of Yield Surfaces for Structured Aniso-tropic Soft Soils
}

\author{
Nallathamby Sivasithamparam ${ }^{1}$, Jorge Castro ${ }^{2}$ \\ ${ }^{I}$ Computational Geomechanics Division, Norwegian Geotechnical Institute (NGI), Oslo, Norway \\ ${ }^{2}$ Department of Ground Engineering and Material Science, University of Cantabria, Santander, Spain \\ E-mails: 'nallathamby.siva@ngi.no (corresponding author); ${ }^{2}$ castrogj@unican.es
}

\begin{abstract}
A framework based on logarithmic contractancy is proposed to produce versatile shapes of yield surfaces for structured anisotropic clays. The recently proposed constitutive model (E-SCLAY1S) is an extension of existing model called S-CLAY1S, which is a Cam Clay type model that accounts for anisotropy and structure. A new parameter called contractancy parameter is introduced to control the shape of the yield surface as well as the plastic potential (as an associated flow rule is applied). This new parameter can be used to fit the coefficient of earth pressure at rest, the undrained shear strength or the stiffness under shearing stress paths predicted by the model. The model predicts the uniqueness of the critical state line and its slope is independent of the contractancy parameter. The effect of the shape of the yield surface was investigated on computed results of a benchmark embankment constructed on Bothkennar (Scotland) clay by employing the E-SCLAY1S model as a user-defined soil model into the PLAXIS finite element code. The results demonstrate that the contribution of the shape of yield surface (logarithmic contractancy parameter) have a relatively large effect on lateral movement of subsoil beneath the toe of the embankment compared to the settlement of subsoil at the centre of the embankment.
\end{abstract}

Keywords: logarithmic contractancy, yield surface, anisotropy, destructuration, soft soils, embankment.

Conference topic: Design experiences and theoretical solutions.

\section{Introduction}

Since the pioneering work of Roscoe and co-workers (Roscoe et al. 1958, 1963; Schofield, Wroth 1968), many constitutive models have been proposed in the framework of Critical State soil mechanics. Hence, the shapes of the yield and plastic potential surfaces vary from model to model in the literature. A constitutive model that is able to reproduce a variety of shapes (yield surfaces) could provide predictions that are more accurate.

Natural soft soil deposits exhibit inherent anisotropic behaviour due to its deposition history as well as bonding (structure) and destructuration during loading. Therefore, several constitutive models, which account for anisotropy have been proposed in the literature (e.g. Sekiguchi, Ohta 1977; Dafalias 1986; Whittle, Kavvadas 1994; Wheeler et al. 2003). The major differences between these models are shape of the yield surface and rotational hardening rule. The S-CLAY1S model (Karstunen et al. 2005) has been proposed by considering a rotated and distorted elliptical yield surface to account for anisotropy and an intrinsic yield surface to reproduce soil structure (bonding). The S-CLAY1S model has proven its ability to reproduce the behaviour of normally or slightly overconsolidated structured soft clays (Karstunen et al. 2005, 2006; Karstunen, Koskinen 2008; Yildiz et al. 2009).

In general, S-CLAY1S's predictions of lateral movement of subsoil beneath the toe of embankments built on soft soils using coupled soil/water finite element code often overestimate or underestimate valued measured in the field, although computed surface settlements of subsoil show a good agreement with measurements (Karstunen et al. 2005, 2006; Karstunen, Koskinen 2008; Yildiz et al. 2009). One of the factors for unrealistic computed lateral movement is the employed shape of the yield surface shape (associated flow rule) of the constitutive model, or similarly, prediction of $K_{0}$ value for compression loading.

The recently proposed E-SCLAY1S (Sivasithamparam, Castro 2016) is an extension of the S-CLAY1S model (Karstunen et al. 2005) using the framework of logarithmic contractancy (Ohta et al. 2011) to include some flexibility in the shape of the yield surface. The model introduces an additional parameter, called the contractancy parameter, which controls the shape of the yield surface. The contractancy parameter can be related to the coefficient of earth pressure at rest for normally consolidated conditions, $K_{0 \mathrm{NC}}$, the undrained shear strength, $c_{u}$, or the stiffness under shearing stress paths. In this way, E-SCLAY1S, extends the predictive capabilities of the S-CLAY1S model, while including just an additional parameter with clear physical meaning. The E-SCLAY1S model has the flexibiltity using the additional contractancy parameter to control the predicted $K_{0}$ value (i.e. shape of yield surface) while keeping the same critical state line in the stress space.

In this study, the authors investigate the effect of shape of the yield surfaces (influence of contractancy parameter) on a benchmark embankment built on Bothkennar soft clay by numerical simulation using the PLAXIS 
finite element code and using the E-SCLAY1S model as a user-defined soil model. The first section of the paper gives a short description of the E-SCLAY1S model in triaxial stress space and its important features. Following sections present the details of numerical analyses of benchmark embankment, discussion of results and conclusions.

\section{Logarithmic Contractancy model (E-SCLAY1S)}

The recently proposed E-SCLAY1S model (Sivasithamparam, Castro 2016) is an extension of the S-CLAY1S (Karstunen et al. 2005) model, which accounts for anisotropy and destructuration. Anisotropy of plastic behaviour is represented through an inclined and distorted yield surface and a rotational hardening law to model the development or erasure of fabric anisotropy during plastic straining; while interparticle bonding and degradation of bonds (structure) is reproduced using intrinsic and natural yield surfaces (Gens, Nova 1993) and a hardening law describing destructuration as a function of plastic straining. For the sake of simplicity, the mathematical formulation is presented in the following in triaxial stress space, which can be used only to model the response of crossanisotropic samples (cut vertically from the soil deposit) subjected to oedometer or triaxial loading.

The yield surface of the E-SCLAY1S model (see Fig. 1), which introduces an additional degree of freedom in the shape of the yield surface using the framework of logarithmic contractancy (Ohno et al. 2007) is given as

$$
f_{y}=\left(1+\frac{|\eta-\alpha|^{n_{L}}}{M^{n_{L}}-\alpha^{n_{L}}}\right)^{\Psi}-\frac{p_{m}^{\prime}}{p^{\prime}}=0,
$$

where $\Psi$ is an intermediate parameter and is given as

$$
\Psi=\frac{(M-\alpha)}{n_{L} M}\left[1+\frac{M^{n_{L}}-\alpha^{n_{L}}}{(M-\alpha)^{n_{L}}}\right],
$$

and $n_{L}$ is a new parameter (contractancy parameter) that controls the shape of the yield surface. The subscript " $L$ " refers to logarithmic contractancy, following the notation by Ohta et al. (2011). The E-SCLAY 1S preserves the hierarchical development of S-CLAY1S, as E-SCLAY1S reduces to S-CLAY1S for $n_{L}=2$, i.e. Eq. (2) reduces as $\Psi=1$.

As in the S-CLAY1S model, the effect of bonding in the E-SCLAY1S model is described by an intrinsic yield surface (Gens, Nova 1993), which has the same shape and inclination of the natural yield surface but with a smaller size. The size of the intrinsic yield surface is specified by the state parameter $p_{m i}^{\prime}$, which is related to the size $p_{m}^{\prime}$ of the natural yield surface by the state parameter $\chi$ as the current amount of bonding

$$
p_{m}^{\prime}=(1+\chi) p_{m i}^{\prime} .
$$

The E-SCLAY1S model adopts three hardening rules from S-CLAY1S, namely isotropic hardening, rotational hardening and degradation of bonds rule. The main features of the model are discussed below.

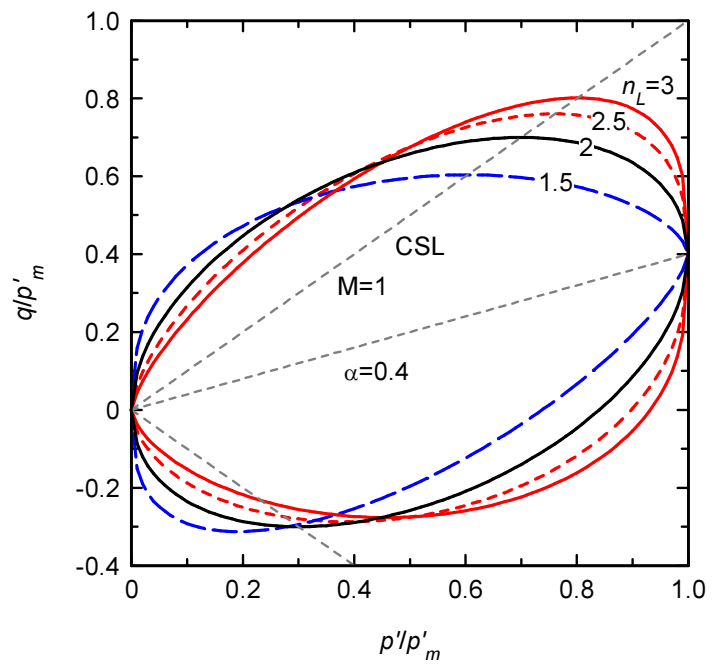

Fig. 1. Different shapes of the yield surface for E-SCLAY1

Prediction of unique critical state line: for anisotropic contractancy models, the slope of the critical state line (CSL) is not usually unique (e.g. extended Sekiguchi-Ohta models, Sekiguchi-Ohta 2001) and it depends on both slope of critical state $(M)$ and logarithmic contractancy $\left(n_{L}\right)$. The E-SCLAY 1S was formulated such a way that to preserve $M$ as the slope of the CSL for any $n_{L}$ values (see Fig. 2).

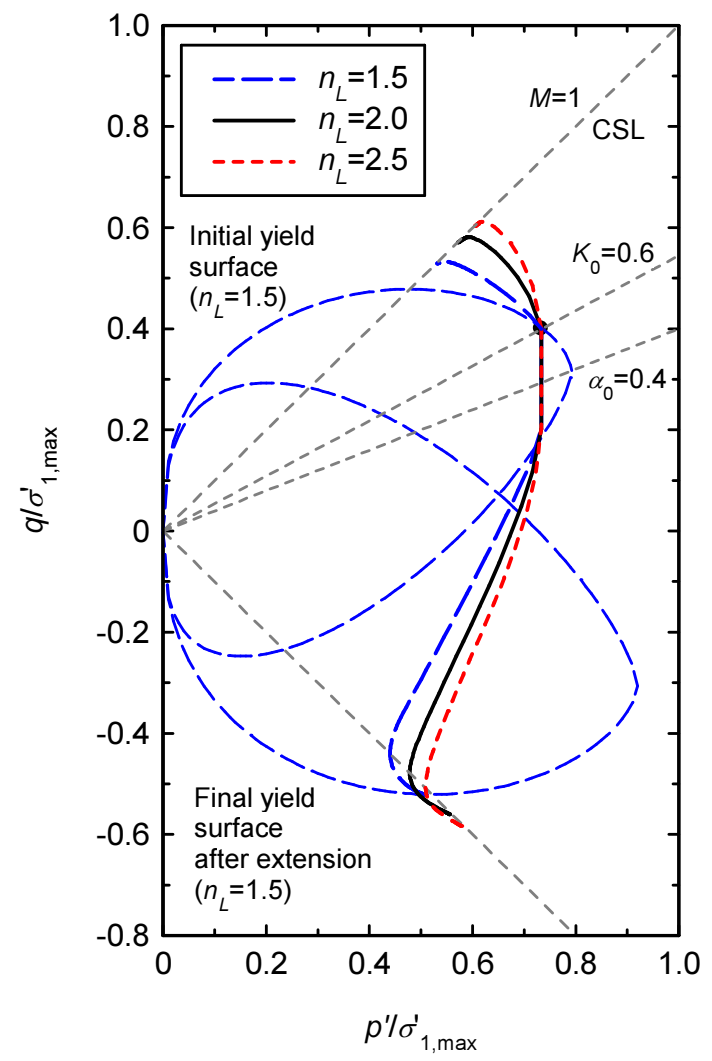

Fig. 2. Predicted unique critical state line for varying $n_{L}$ values 
Variation in $K_{0}$ predcition depending on contractancy parameter: the E-SCLAY1S model gives higher degree of freedom to fit the desired $K_{0}$ value. The variation of the $K_{0}$ stress path with varying $n_{L}$ is illustrated in Figure 3 for an initially isotropically consolidated soil sample.

Variation in predicted undrained shear strength depending on contractancy parameter: the additional parameter $n_{L}$ in E-SCLAY $1 \mathrm{~S}$ allows for a perfect matching of undrained shear strength. The variation of undrained shear strength predicted by isotropic version of the model depending on $n_{L}$ is shown in Figure 4.

Further details of the model, its mathematical formulation in general stress space and its implementation into the PLAXIS FE code can be found in Sivasithamparam, Castro (2016).

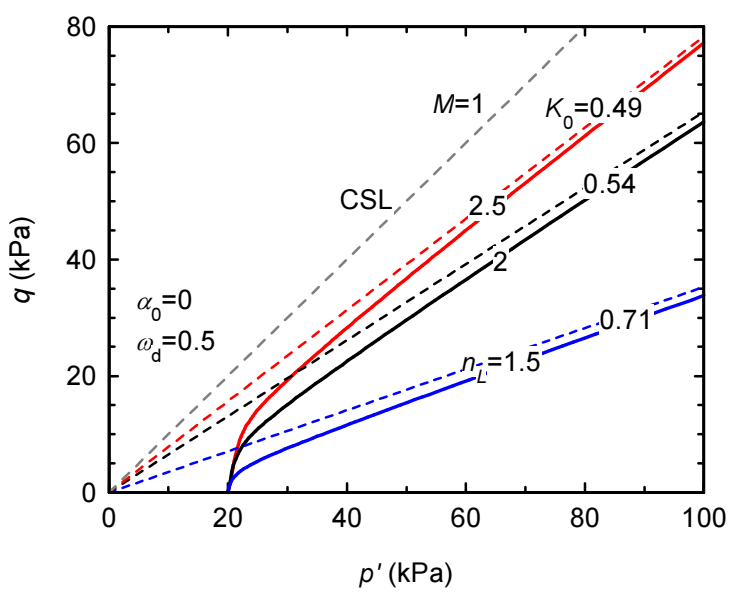

Fig. 3. Predicted $K_{0}$ stress paths for varying $n_{L}$ values.

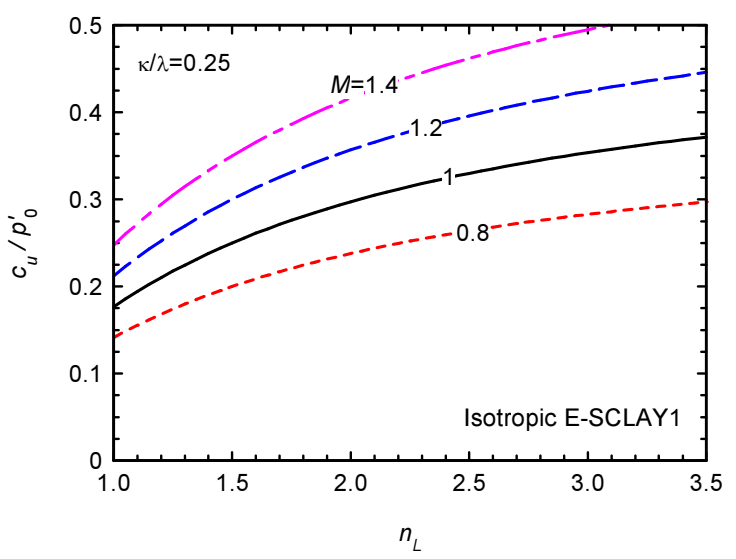

Fig. 4. Predicion of $c_{u}$ for isotropically normally consolidated samples

\section{Numerical analyses of a benchmark embankment}

The performance of the recently proposed E-SCLAY1S model was analysed in finite elemnt benchmark problem using PLAXIS FE code and their results are presented in this section. A benchmark embankment problem was selected to represent a typical geotechnical engineering problem where anisotropy and structure might play a role. Finite element analyses were performed with PLAXIS 2D AE version and the E-SCLAY1S model which has been implemented as a user-defined soil model.

An embankment constructed on soft soil is assumed $2 \mathrm{~m}$ high, with a width at the top of $8 \mathrm{~m}$ and the side slopes with a gradient of $1: 4$. The soft soil is assumed to have the properties of soft Bothkennar clay, which extends for $20 \mathrm{~m}$ depth. At the surface, there is a $1 \mathrm{~m}$ thick over-consolidated dry crust. The geometry of the embankment and the finite element mesh used are shown in Figure 5. The groundwater table is assumed to be located at $1 \mathrm{~m}$ below the ground surface.

Bothkennar clay material has been extensively studied and consistent set of laboratory data are available to derive material parameters for the E-SCLAY1S (e.g., Géotechnique Symposium-in-Print 1992, McGinty 2006) in a consistent manner. Table 1 gives the values for the initial state variables as well as the conventional soil constants for Bothkennar clay as required for the E-SCLAY1S model. The permeability is assumed to be the same in the vertical and horizontal direction for the sake of simplicity.

The embankment, which is assumed to be made of granular material, was modelled using a simple linear elastic perfectly plastic model (Mohr-Coulomb model); see Table 1 for material parameters. In order to make the results fully comparable, the over-consolidated dry crust layer is also modelled with the Mohr-Coulomb model (see Table 1 for material parameters). This embankment problem is hence expected to be dominated by the soft soil response and is not very sensitive to the embankment and dry crust parameters.

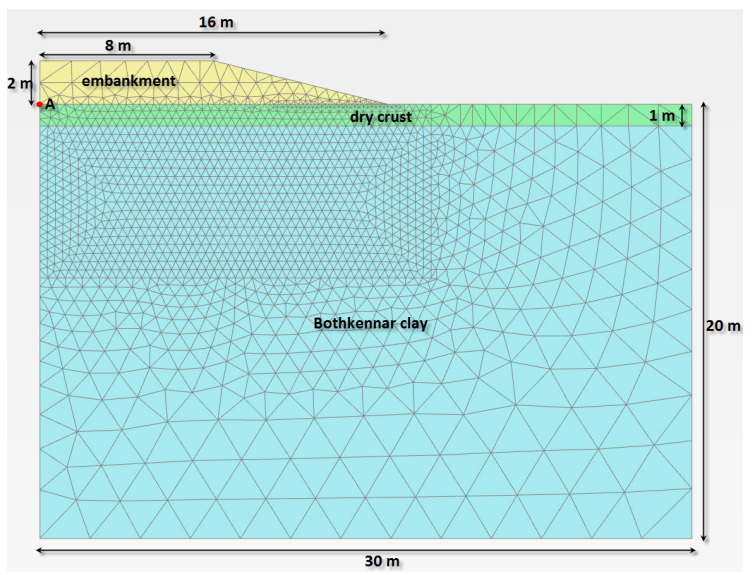

Fig. 5. Finite element mesh and geometry of the benchmark embankment

The analyses were performed using small deformation assumption as the idea is just to compare the influence of the logarithmic contractancy parameter $\left(n_{L}\right)$ at a boundary value level. The construction of the embankment was simulated by two undrained phases of 5 days each. In all analyses, drained conditions and zero initial pore pressures have been assumed above the water table. 
For the initial condition, the in-situ $K_{0}$ value was assumed to be $K_{0}=0.5$ due to the slight overconsolidation of Bothkennar clay. The first construction phase, in which the first layer of the embankment was built, was followed by a 5-day consolidation stage. After the completion of the second layer ofthe embankment, the final consolidation was simulated until 3000 days.

The comparison between the results for varying $n_{L}$ of the finite element simulations are presented in Figure 6 and Figure 7 using different colour for different $n_{L}$ values. The predicted horizontal displacements versus depth under the toe of the embankment after 3000 days of embankment construction for varying $n_{L}$ values of the E-SCLAY1S model are presented in Figure 6. The settlement predictions versus time at the node directly under the centreline of the embankment (point A in Fig. 5) are presented in Figuer 7 for 3000 days of consolidation after the completion of embankment construction. It is seen from Figure 6 and Figure 7 that the contractancy paratmeter $n_{L}$ of the E-SCLAY1S model has a significant effect on lateral (horizontal) deformation of subsoil beneath the toe of the embankment compared to settlement of subsoil at the centre of the embankment. Further, the shape of horizontal displacement profile with deth does not change with $n_{L}$. Ohno et al. (2007) presented similar results using the Sekiguchi-Ohta model (Sekiguchi, Ohta 1977).

Table 1. The S-CLAY1S model values for state variables, conventional soil constants and additional parameters used to control evolutions of anisotropy for Bothkennar clay

\begin{tabular}{|c|c|}
\hline Parameter & Value \\
\hline \multicolumn{2}{|l|}{$\underline{\text { Soil constants }}$} \\
\hline$\kappa$ & 0.02 \\
\hline$v^{\prime}$ & 0.2 \\
\hline$\lambda_{i}$ & 0.18 \\
\hline$M$ & 1.51 \\
\hline$\gamma\left(\mathrm{kN} / \mathrm{m}^{3}\right)$ & 16.5 \\
\hline$k_{x}=k_{y}(\mathrm{~m} /$ day $)$ & $2.5 \mathrm{E}-4$ \\
\hline \multicolumn{2}{|l|}{$\underline{\text { State variables }}$} \\
\hline$e_{0}$ & 2.0 \\
\hline OCR & 1.5 \\
\hline$\alpha_{0}$ & 0.59 \\
\hline$\chi_{0}$ & 8.0 \\
\hline \multicolumn{2}{|c|}{ Additional anisotropy parameters } \\
\hline$\mu$ & 50 \\
\hline$\beta$ & 1 \\
\hline \multicolumn{2}{|c|}{ Additional destructuration parameter } \\
\hline$\omega$ & 9.0 \\
\hline$\omega_{d}$ & 0.2 \\
\hline
\end{tabular}

Table 2. Soil parameters of dry crust and sand layer

\begin{tabular}{c|c|c}
\hline Parameter & Crust & Sand \\
\hline$\gamma\left(\mathrm{kN} / \mathrm{m}^{3}\right)$ & 19.0 & 20.0 \\
\hline $\mathrm{E}^{\prime}(\mathrm{kPa})$ & 3000.0 & 40000.0 \\
\hline$v^{\prime}$ & 0.2 & 0.35 \\
\hline $\mathrm{c}^{\prime}$ & 2.0 & 0.0 \\
\hline$\varphi^{\prime}$ & 37.1 & 40.0 \\
\hline$\psi^{\prime}$ & 0.0 & 0.0 \\
\hline $\mathrm{k}_{\mathrm{x}}=\mathrm{k}_{\mathrm{y}}(\mathrm{m} /$ day $)$ & $8.64 \mathrm{E}-5$ & $1.0 \mathrm{E}-3$ \\
\hline \multicolumn{2}{|c}{}
\end{tabular}

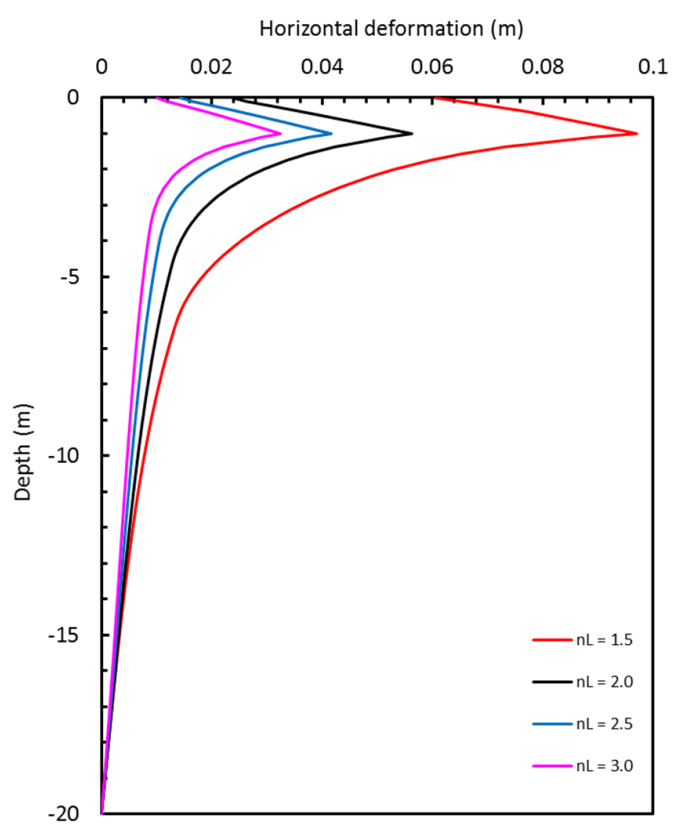

Fig. 6. Comparison of final horizontal displacement predictions at the embankment toe after 3000 days

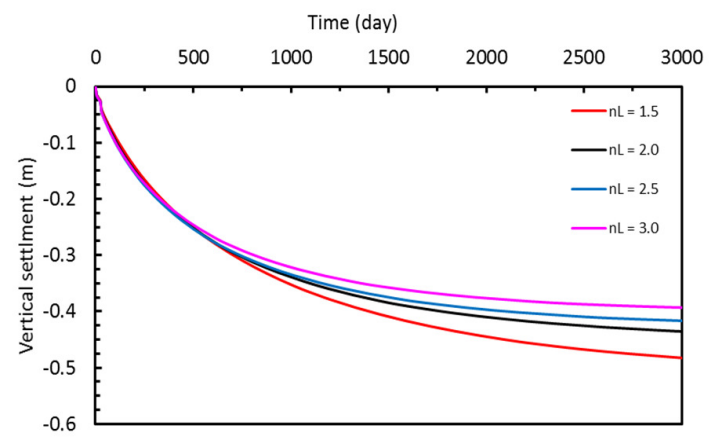

Fig. 7. Comparison of time settlement curves at point $\mathrm{A}$ 


\section{Discussion and conclusions}

The paper studies the influence of the contractancy parameter $n_{L}$ of the recently proposed logarithmic contractancy E-SCLAY1S model in a typical benchmark embankment on soft Bothkennar clay. The E-SCLAY1S model is an extension of previous anisotropic model for structured clays (S-CLAY1S) under normally or slightly over-consolidated conditions. The extension done using the framework of logairhtmic contractancy. The simulation of the benchmark embankment constructed on soft soils demonstrate that the effects of the contractancy parameter $n_{L}$ are large on the lateral movement of subsoils compared to that on the vertical settlement of subsoil below the centre of the embankment.

\section{Acknowledgements}

The authors would like to acknowledge the valuable suggestions and insights offered by Prof. Minna Karstunen at Chalmers University of Technology, Sweden and Department of Civil Engineering, University of Strathclyde, Glasgow, UK.

\section{Funding}

The research was carried out as part of GEO-INSTALL (Modelling Installation Effects in Geotechnical Engineering, PIAP-GA-2009-230638) project supported by the European Community through the programme Marie Curie Industry-Academia Partnerships and Pathways (IAPP) under the $7^{\text {th }}$ Framework programme.

\section{Contribution}

Nallathamby Sivasithamparam contributed to conception, implementation of the model and benchmark calculation as well as writing the paper.

Jorge Castro contributed to further development of the model and validation in a single element level as well as writing the paper.

\section{Disclosure statement}

There is no competing financial, professional, or personal interests from other parties.

\section{References}

Dafalias, Y. F. 1986. An anisotropic critical state soil plasticity model, Mechanical Research Communications 13(6): 341-347. http://dx.doi.org/10.1016/0093-6413(86)90047-9

Géotechnique Symposium-in-Print. 1992. Géotechnique 42(2).

Gens, A.; Nova, R. 1993. Conceptual bases for a constitutive model for bonded soils and weak rocks, in A. Anagnostopoulos, F. Schlosser, N. Kaltesiotis, R. Frank (Eds.). Geomechanical engineering of hard soils and soft rocks. Rotterdam: Balkema, 485-494.
McGinty, K. 2006. The stress-strain behaviour of Bothkennar clay: $\mathrm{PhD}$ thesis. Department of Civil Engineering, University of Glasgow, UK.

Karstunen, M.; Krenn, H.; Wheeler, S. J.; Koskinen, M.; Zentar, R. 2005. Effect of anisotropy and destructuration on the behaviour of Murro test embankment, International Journal of Geomechanics 5(2): 87-97. http://dx.doi.org/10.1061/(ASCE)1532-3641(2005)5:2(87)

Karstunen, M.; Koskinen, M. 2008. Plastic anisotropy of soft reconstituted clays, Canadian Geotechnical Journal 45(3): 314-328. http://dx.doi.org/10.1139/T07-073

Karstunen, M.; Wiltafsky, C.; Krenn, H.; Scharinger, F.; Schweiger, H. F. 2006. Modelling the behaviour of an embankment on soft clay with different constitutive models, International Journal for Numerical and Analytical Methods in Geomechanics 30: 953-982. http://dx.doi.org/10.1002/nag.507

Ohno, S.; Takeyama, T.; Pipatpongsa, T.; Ohta, H.; Iizuka, A. 2007. Analysis of embankment by nonlinear contractancy description, in Proceedings of the $13^{\text {th }}$ Asian Regional Conference of Soil Mechanics and Geotechnical Engineering, 1097-1100.

Ohta, H.; Iizuka, A.; Ohno, S. 2011. Constitutive modelling for soft cohesive soils, in S. Iai (Ed.).Geotechnics and earthquake geotechnics towards global sustainability, Chapter 13. Dordrecht: Springer, 231-250.

Roscoe, K. H.; Schofield, A. N.; Wroth, C. P. 1958. On the yielding of soils, Géotechnique 8(1): 22-53. http://dx.doi.org/10.1680/geot.1958.8.1.22

Roscoe, K. H.; Schofield, A. N. 1963. Mechanical behaviour of an idealised 'wet' clay, in Proceedings of the Second European Conference on Soil Mechanics Foundation Engineering, Wiesbaden, Germany, 47-54.

Schofield, A. N.; Wroth, C. P. 1968. Critical state soil mechanics. London: McGraw-Hill.

Sekiguchi, H.; Ohta, H. 1977. Induced anisotropy and time dependency in clays, in Proc specialty session 9, Constitutive equation of soils, $9^{\text {th }}$ international conferenceon soil mechanics and foundation engineering, 1977, Tokyo, Japan, 306-315.

Sivasithamparam, N.; Castro, J. 2016. An anisotropic elastoplastic model for soft clays based on logarithmic contractancy, International Journal for Numerical and Analytical Methods in Geomechanics 40: 596-621. http://dx.doi.org/10.1002/nag.2418

Wheeler, S. J.; Naatanen, A.; Karstunen, K.; Lojander, M. 2003. An anisotropic elastoplastic model for soft clays, Canadian Geotechnical Journal 40(2): 403-418. http://dx.doi.org/10.1139/t02-119

Whittle, A. J.; Kavvadas, M. J. 1994. Formulation of MIT-E3 constitutive model for overconsolidated clays, Journal of Geotechnical Engineering ASCE 120(10): 173-198.

http://dx.doi.org/10.1061/(ASCE)0733-9410(1994)120:1(173)

Yildiz, A.; Karstunen, M.; Krenn, H.2009. Effect of anisotropy and destructuration on behavior of Haarajoki test embankment, 1 International Journal of Geomechanics 9: 153-168.

http://dx.doi.org/10.1061/(ASCE)1532-3641(2009)9:4(153) 